\title{
Regulation of population size of arborescent octocorals on shallow Caribbean reefs
}

\author{
Peter J. Edmunds ${ }^{1, *}$, Howard R. Lasker ${ }^{2}$ \\ ${ }^{1}$ Department of Biology, California State University, 18111 Nordhoff Street, Northridge, CA 91330-8303, USA \\ ${ }^{2}$ Department of Geology and Department of Environment and Sustainability, University at Buffalo, State University of New York, \\ 411 Cooke Hall, Buffalo, NY 14260, USA
}

\begin{abstract}
The coral reef crisis is defined by declining cover of scleractinians, but on Caribbean reefs it also is associated with increasing abundances of octocorals. The demographic causes of these increases are not understood, but parallels between marine 'forests' of octocorals, and terrestrial forests of trees (e.g. formation of a 3-dimensional framework providing habitat), suggests that insights into causation might be found by comparing the 2 types of forest. This study describes communities of octocorals in St. John, US Virgin Islands, and evaluates their dynamics for goodness of fit to a construct reflecting 2 processes structuring terrestrial forests: self-thinning and density-dependent recruitment. Octocorals $(>5 \mathrm{~cm}$ tall) were censused on 6 reefs (7-9 m depth) from 2014-2017, thus revealing differences among years in their density and height. At 5 sites, this variation was inconsistent with selfthinning, but at the 6th, there was a trend for densities to decline and height to increase, with these effects largely attributed to Eunicea spp.; this pattern is consistent with several processes, one of which is self-thinning. For recruits $(\leq 5 \mathrm{~cm}$ tall), densities differed among sites and times, but neither density nor per capita recruitment were density-dependent. For Eunicea spp., the recruit density was positively associated with adult density in 2014 , and per capita recruitment was inversely related to adult density in 3 of 4 years. These results highlight the challenges of inferring that common mechanisms structure animal and plant forests, and they underscore the complexity of processes contributing to the recent population growths of Caribbean octocorals.
\end{abstract}

KEY WORDS: Octocorallia $\cdot$ Soft corals $\cdot$ Ecology · Population · Coral reef

${ }^{*}$ Corresponding author: peter.edmunds@csun.edu

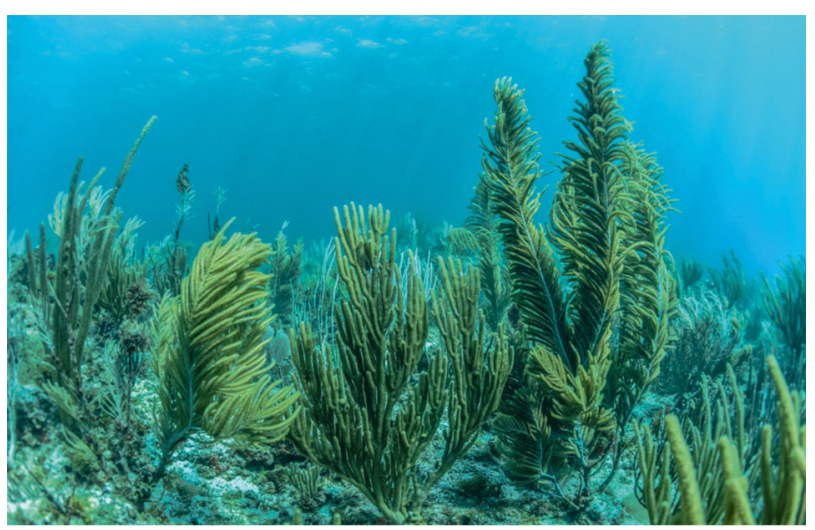

Octocoral forest at $\sim 6 \mathrm{~m}$ depth in St. John, where dense aggregates of colonies have the potential to affect octocoral recruitment and colony success.

Photo: Peter J. Edmunds

\section{INTRODUCTION}

The factors regulating population size are foundational to ecology (Haldane 1953, Murdoch 1994), but in most cases more is known about net changes in population size than the demographic processes causing them to occur. This is an important gap in knowledge for many ecosystems that affects the ability to accurately project changes in population size into the future (Urban et al. 2016). While records of historic abundance can support extrapolations of future population sizes (Thomas et al. 2004), without knowledge of the vital rates controlling population growth, projections are prone to inaccuracies, and cannot be adjusted to accommodate varying conditions, or to detect signs of impending demographic collapse (Hughes \& Tanner 2000, Caswell 2001).

() The authors 2019. Open Access under Creative Commons by Attribution Licence. Use, distribution and reproduction are unrestricted. Authors and original publication must be credited. 
The limitations in understanding the demographics of changing population sizes are striking when the objective is population projection (sensu Caswell 2001), as is commonplace when the biological effects of global climate change are being considered (Urban et al. 2016). Coral reefs exemplify these limitations, because many have experienced extensive mortalities of their framework-building scleractinians (Bruno \& Selig 2007, Jackson et al. 2014), and they are likely to undergo additional changes in community structure in the future (van Hooidonk et al. 2014, Hughes et al. 2018a,b). Future changes probably will involve declines in coral cover, changes in assemblage structure (Hughes et al. 2018a,b), and enhanced macroalgal blooms, particularly in the Caribbean (Roff \& Mumby 2012). However, a few reefs contradict these trends (Graham et al. 2011, Guest et al. 2018, Holbrook et al. 2018), and in some cases the recent changes have affected taxa other than scleractinians and macroalgae (Norström et al. 2009), favoring, for example, octocorals (Stobart et al. 2005, Ruzicka et al. 2013, Lenz et al. 2015).

Among the numerous coral reefs where shifts in benthic communities have occurred, the demographic processes driving the declines in scleractinian abundance have been described in a surprisingly small number of cases (e.g. Hughes 1984, Hughes \& Jackson 1985, Babcock 1991, Edmunds \& Elahi 2007, Riegl et al. 2017, and references therein). Limited understanding of the demographic controls of population size extends to most benthic taxa on coral reefs, with notable exceptions involving select octocorals (e.g. Lasker 1990, Yoshioka 1996, Bruno et al. 2011, Gomez et al. 2018), sponges (McMurray et al. 2017), echinoids (Lessios et al. 2001, Levitan et al. 2014), and asteroids (McCallum 1990, Pratchett 2005). Faced with changing abundances of multiple benthic taxa on coral reefs, ecologists find themselves with a shortfall of demographic tools with which they can explain the causes of the changes. The consequences of this shortfall are evident in efforts to understand the causes of recent increases in abundances of octocorals on Caribbean reefs (Ruzicka et al. 2013, Lenz et al. 2015, Edmunds \& Lasker 2016, Tsounis et al. 2018), and signs that they have greater ecological resilience versus scleractinians (Tsounis \& Edmunds 2017). Ecological theory suggests that the causes of these trends are likely to operate in density-dependent (DD) ways (Sale \& Tolimieri 2000, Hixon et al. 2002), such that the balance between inverse DD and direct DD regulates population size, and shifts in this balance lead to populations differing in size over time and space.
With little demographic information for most Caribbean octocorals, it is difficult to select potential mechanisms regulating their population size in an a priori fashion. One relatively new domain of reasoning that might facilitate this selection is the parallel that has been drawn between marine animal forests and terrestrial forests (Rossi et al. 2017), and the inference that assemblages of arborescent octocorals are animal forests (Rossi et al. 2017, Sanchez 2017). Multiple features support this inference, but the most striking involve the common creation of 3-dimensional frameworks with high structural complexity and the capacity to provide shelter to multiple species (Rossi et al. 2017). The absence of nutritive roots and a basal-distil transport system underscore the imperfections in the analogy between animal and terrestrial forests. In terrestrial forests, DD is important in determining population size (Weller 1987, Condit et al. 1994, Harms et al. 2000), with 2 common forms involving recruitment (Wills et al. 1997), and selfthinning (ST) (Westoby 1984, Weller 1987). Recruitment in terrestrial forests can range from direct DD to inverse DD (Condit et al. 1994, Harms et al. 2000), and ST posits that crowding (i.e. high densities) in even-aged plant stands causes resource competition leading to mortality and increases in size of the surviving plants (Westoby 1984). Classically, ST is visualized using a double logarithmic plot of size (biomass) against density (organisms area ${ }^{-1}$ ), on which the slope commonly is considered to be -1.5 (White 1981, Westoby 1984), although empirical slopes are lower (Weller 1987, Lonsdale 1990). In the marine environment, DD recruitment is well known (Caley et al. 1996, Hixon et al. 2002), and several cases of ST have been described (Frechette \& Lefaivre 1995, Guinez 2005), with octocorals providing examples of both DD recruitment and ST (Linares et al. 2008, Privitera-Johnson et al. 2015, Cau et al. 2016).

Here we explore the role of DD in determining octocoral abundances at 6 sites along the south coast of St. John, US Virgin Islands. At these sites, the benthic communities defined by scleractinians, the hydrozoan Millepora, macroalgae, and 'crustose coralline algae, algal turf, and bare space' (CTB) have been studied for 27 yr (Edmunds 2013, 2018). Octocoral abundances have been reconstructed from photoquadrats over the same period (Edmunds \& Lasker 2016), and in the present analyses, we describe in situ surveys of octocorals (for density and size) that were completed from 2014 to 2017. Based on data averaged by site and year, we evaluated variation in these state variables for evidence of DD recruitment and ST. First, we tested the hypothesis 
that octocoral density and height varied among sites and times, and used this analysis as a precursor to evaluating whether such variation conformed to DD recruitment or ST. Second, we tested the density of recruits (colonies $\leq 5 \mathrm{~cm}$ tall), and per capita recruitment, for a linear association with adult density (colonies $>5 \mathrm{~cm}$ tall) to detect DD. Finally, to explore

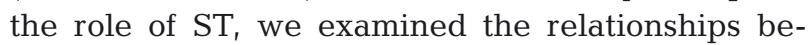
tween colony height (a proxy for biomass) and density for adults, both within a year (i.e. a static measure of ST; Westoby 1984), and among years within sites (i.e. a dynamic measure of the impacts of ST in favoring growth of surviving organisms; Westoby 1984). Our analyses provide correlative tests for DD recruitment and ST, but they cannot establish cause and effect. Moreover, the test for DD recruitment is made equivocal by the likelihood that these populations are demographically open (and, therefore, not subject to DD supply of recruits), and the possibility that larval settlement and post-settlement success may be subject to independent DD processes.

\section{MATERIALS AND METHODS}

\subsection{Field surveys}

Surveys were completed at 6 sites on shallow (7-9 $\mathrm{m}$ depth) fringing reefs on the south shore of St. John, U.S. Virgin Islands, between Cabritte Horn and White Point (Fig. 1). In 1992, these sites were randomly selected on hard substrata along $4.5 \mathrm{~km}$ of shore between these headlands (Edmunds 2013), and they have been censused annually up to the present. Each site consists of a permanently marked transect that has been $40 \mathrm{~m}$ long since 2000 . The present project began in 2014 with the objective of augmenting a long-standing analysis of benthic community structure (which emphasized scleractinians; Edmunds 2013) with new analyses focused on octocorals (Tsounis et al. 2018). As part of this effort, arborescent octocorals were surveyed in situ with genus resolution, using 40 quadrats $(0.5 \times 0.5 \mathrm{~m})$ placed at random, non-overlapping positions along the same transect (and re-randomized annually) located at each of the 6 sites. Surveys were completed over 4 wk beginning on 20 July in each year from 2014 to 2017 , and were conducted by counting and measuring the height of octocorals attached by holdfasts within each quadrat. Height was determined $( \pm 1 \mathrm{~cm})$ using a flexible tape measure stretched from the holdfast to the colony apex. Abundances were analyzed separately for adults ( $>5 \mathrm{~cm}$ tall), and recruits $(\leq 5 \mathrm{~cm}$ tall), with this size cut-off based on the maximal height to which the recruits of most octocoral species are likely to grow in 1 yr (Lasker 1990, 2013). While the benthos was inspected for all small octocorals, sampling efficiency probably was low for recruits consisting of only a few polyps (i.e. $<1 \mathrm{~cm}$ tall). Analyses testing for the effects of DD and ST were first completed for octocorals pooled among taxa, and second for the 3 most common genera of octocorals. Evidence of DD recruitment was also sought from analyses of per capita recruitment by site, with these values obtained by dividing the density of recruits by the mean density of adults.

\subsection{Statistical analyses}

Octocoral densities (adults and recruits) and heights were compared among sites in 2014 to test for spatial variation. Quadrats were treated as replicates in contrasts of density, and colonies were treated as replicates in contrasts of height. Sites were contrasted with 1-way ANOVA, densities were square$\operatorname{root}(x+3 / 8)$ transformed (Zar 2010), and the assumptions of ANOVA were tested through graphical analyses of residuals. Multiple comparisons were completed using Tukey HSD procedures. To graphically display changes in octocoral communities over time, bar graphs were used for densities of recruits, and scatter plots showing density (abscissa) and mean colony size (ordinate) for adults. Scatterplots for adults display the ways in which colonies occupied space on the benthos (i.e. density), and volume in the seawater (i.e. height). Sites were categorically clustered into low, medium, and high density by octocoral abundance averaged among years, thus allowing a test for octocoral assemblage dynamics associated with colony density.

The putative mechanisms of DD that we wished to test ultimately relied on interactions among octocoral colonies to affect recruitment, colony density, or colony height, and therefore we tested for these effects at the spatial scale over which such interactions are likely to occur. Sites were used as replicates in most analyses because they are random samples of these shallow communities (Edmunds 2013), and octocoral assemblages were relatively homogeneous within each site. The associations testing for evidence of ST were also evaluated by quadrat at some sites to further resolve the conclusions arising from the site-scale analysis. The quadrat-scale analysis provided a more meaningful test of the slope of the abundance-density relationship at the core of ST 

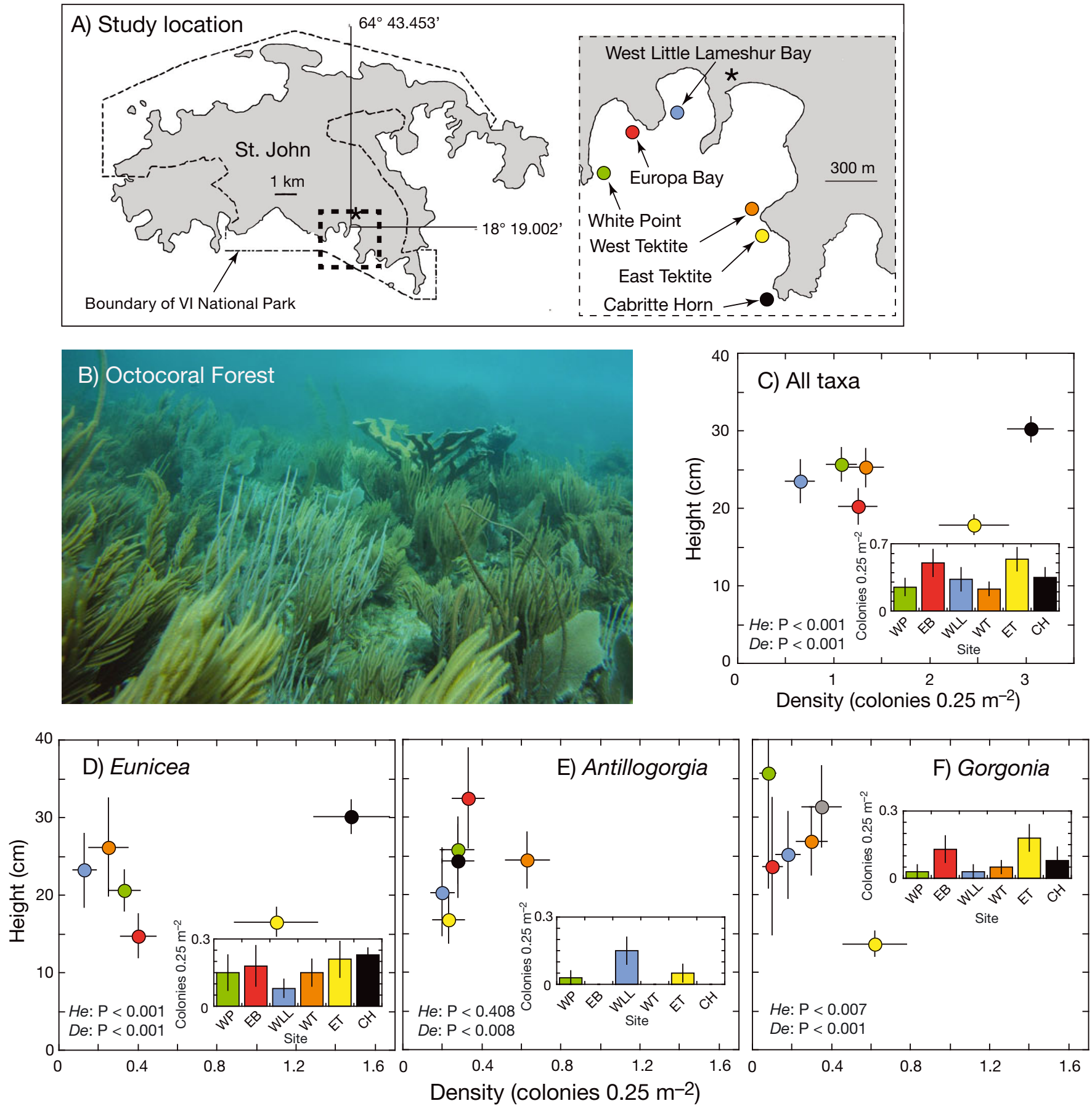

Fig. 1. Study sites and descriptions of octocoral assemblages in 2014. (A) St. John, USVI, showing the location of the Virgin Islands Environmental Resource Station $\left({ }^{*}\right)$ and the study sites between White Point and Cabritte Horn (dashed box). (B) Representative octocoral forest on the eastern side of Cabritte Horn ( 8 m depth) in 2014. (C-F) Octocoral density (De), colony height $(\mathrm{He}$ ), and recruit density (inset bar graph, colonies $\leq 5 \mathrm{~cm}$ tall) for all taxa, Eunicea, Antillogorgia, and Gorgonia, respectively. Mean \pm SE shown based on $n=40$ quadrats for density and a variable number of colonies for height $(C, n=26-96 ; D, n=$ 5-59; E, $\mathrm{n}=8-25 ; \mathrm{F}, \mathrm{n}=3-24$ ). Significance (see Table 1) of among-site contrasts shown in each frame (NS: not significant), with color codes for sites (panel A) that carry through Figs. 2-4 and Figs. S1 \& S2

(Westoby 1984), notably at the scale (i.e. quadrats) at which colony-colony competition occurs.

Evidence of ST (Westoby 1984, Weller 1987) was sought in the results for adult octocorals through: (1) plots of colony size against density by sites within years, in which ST is consistent with an inverse relationship between the 2 variables at high density (i.e. inferred to be approaching saturating biomass) (Weller 
1987); (2) double-logarithmic plots of colony size against density by quadrats and years for sites with high octocoral densities, in which ST is consistent with inverse relationships (Weller 1987, Lonsdale 1990); and (3) changes in size-density relationships averaged by site across 4 years that show declines in density and increases in size (Westoby 1984, Weller 1987).

Evidence for DD recruitment was sought in: (1) scatter plots relating density of recruits to density of adults using values averaged by site within years $(\mathrm{n}=$ 6 sites), and (2) scatter plots relating per capita recruitment to density of adults averaged by site within years $(\mathrm{n}=6$ sites). In these relationships, recruits were operationally defined as colonies $\leq 5 \mathrm{~cm}$ tall, which reflects new individuals detected between surveys (after Caley et al. 1996), and describes the distribution of individuals created by the unresolvable effects of larval delivery, settlement, and postsettlement success. Best-fit relationships describing the trends inherent in the aforementioned plots were obtained by least-squares regressions. Statistical analyses were completed using Systat 13 software.

\section{RESULTS}

\subsection{Overview}

Surveys of octocorals revealed 10 genera, with some quadrats containing no colonies, and others containing up to 8 colonies $0.25 \mathrm{~m}^{-2}$; colonies ranged in height from $\leq 1 \mathrm{~cm}$ (multiple genera at all sites) to $122 \mathrm{~cm}$ (Antillogorgia at Cabritte Horn). The 3 most common genera were Eunicea, Antillogorgia, and Gorgonia. Analyses of the running means of adult density and adult height against sampling effort (number of quadrats or number of colonies), for all 4 years and pooled among taxa, revealed stable values at the maximum sample sizes for the 2 sites at the extremes of the density range (West Little Lameshur and Cabritte Horn). The same was largely true for the densities of Eunicea, Antillogorgia, and Gorgonia, and the sizes of the most common genus, Eunicea (Figs. S1 \& S2 in the Supplement at www.intres.com/articles/suppl/m615p001_supp.pdf). Abundances of Antillogorgia and Gorgonia were low at all sites and in all years, and the running means indicated that heights did not stabilize as a function of sample sizes obtained (Fig. S2). Fewer octocoral recruits were encountered compared to adults, but nevertheless, the running mean density stabilized at the maximum sample size (i.e. $\mathrm{n}=40$ quadrats) for octocorals pooled among taxa, and for Eunicea
(Fig. S3 in the Supplement) for the 2 sites at the extremes of the density range recorded (West Tektite and East Tektite). The running mean density of recruits of Antillogorgia and Gorgonia did not stabilize with 40 quadrats (Fig. S3).

Most $(75 \%, \mathrm{n}=24)$ of the frequency distributions of colony sizes (i.e. recruits + adults), pooled among taxa and separated among years and sites (Fig. S4 in the Supplement), were significantly and positively skewed (based on Fisher's $G_{1} / \mathrm{SE}_{G 1}>2$; Cramer 1997) (Fig. S4). Positive skewing reflected a long tail on the positive side of the mode, with more large, $>40 \mathrm{~cm}$ tall colonies than expected in a normal distribution.

\subsection{Spatial variation}

Overall (i.e. pooled among taxa for 2014), mean adult densities $( \pm \mathrm{SE}, \mathrm{n}=\sim 40)$ ranged from $0.65 \pm$ 0.15 colonies $0.25 \mathrm{~m}^{-2}$ (West Little Lameshur) to $3.05 \pm 0.24$ colonies $0.25 \mathrm{~m}^{-2}$ (Cabritte Horn), with mean heights varying from $18 \pm 1 \mathrm{~cm}$ (East Tektite) to $30 \pm 2 \mathrm{~cm}$ (Cabritte Horn), and mean densities of recruits varying from $0.23 \pm 0.07$ colonies $0.25 \mathrm{~m}^{-2}$ (West Tektite) to $0.54 \pm 0.12$ colonies $0.25 \mathrm{~m}^{-2}$ (East Tektite) (Fig. 1C). Density of adults differed among sites, with higher densities at Cabritte Horn than other sites, higher densities at East Tektite than White Point, and higher densities West Tektite than West Little Lameshur Bay; density of recruits did not differ among sites (Table 1). Heights of adult colonies differed among sites, and were taller at Cabritte Horn than at East Tektite and Europa Bay (Table 1). Similar results were obtained for the 3 most common genera, except that the rank order of sites by adult density and height differed by genus relative to the ranking for pooled taxa. The density of Gorgonia recruits differed among sites, and were lower at West Little Lameshur Bay than Europa Bay and Cabritte Horn (Table 1). The height of adult Eunicea and Gorgonia varied among sites (Antillogorgia did not), with Eunicea taller at Cabritte Horn versus Europa Bay and East Tektite, and Gorgonia taller at Cabritte Horn versus East Tektite (Fig. 1D-F, Table 1).

\subsection{Temporal variation}

\subsubsection{All taxa}

Among-year variation in density and height of adult colonies (pooled among taxa) differed among sites (Fig. 2), with mean density varying from 1.2-fold 


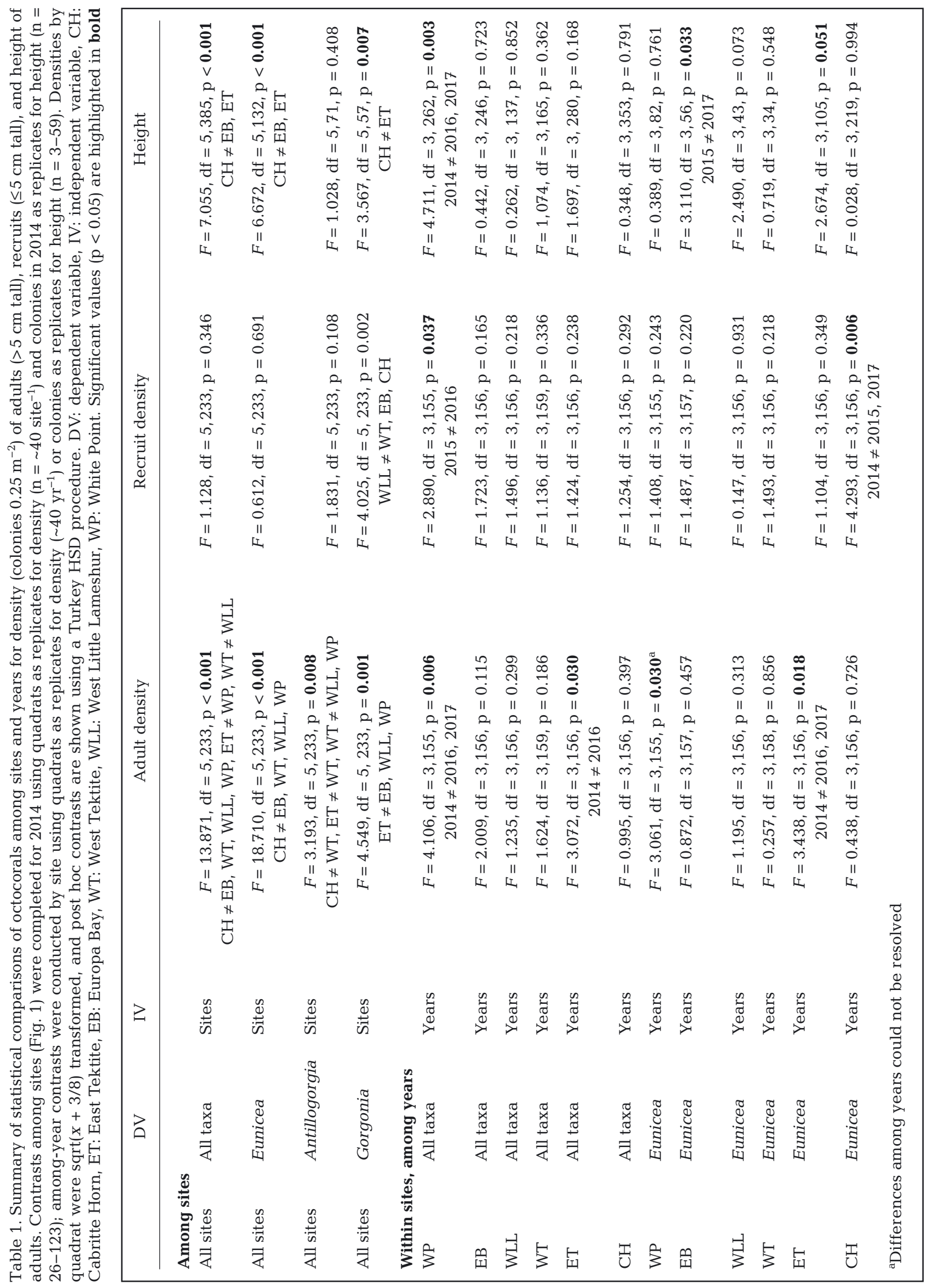




\section{I) All taxa}
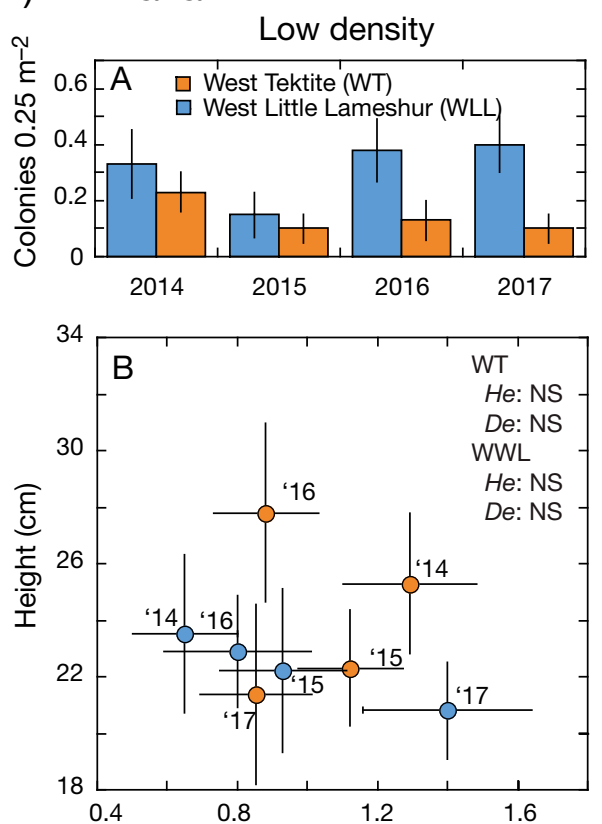

\section{II) Eunicea}
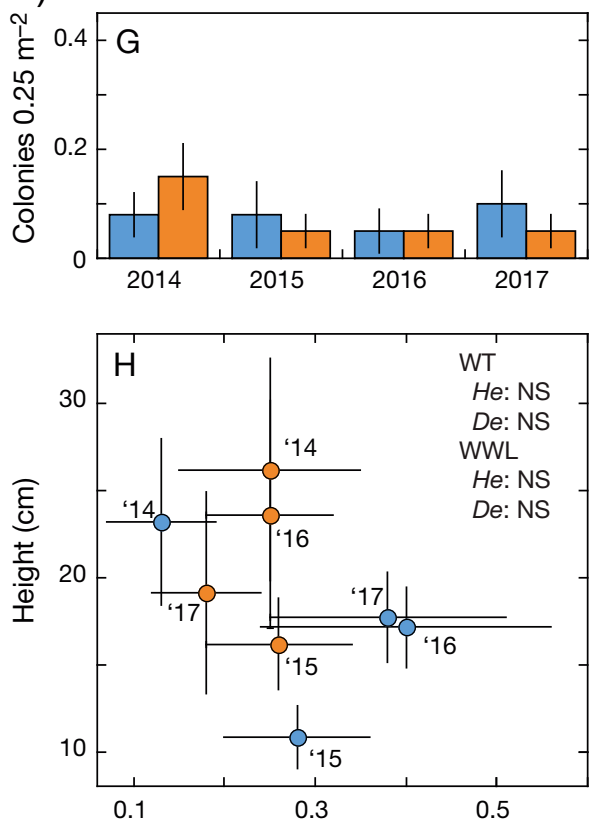
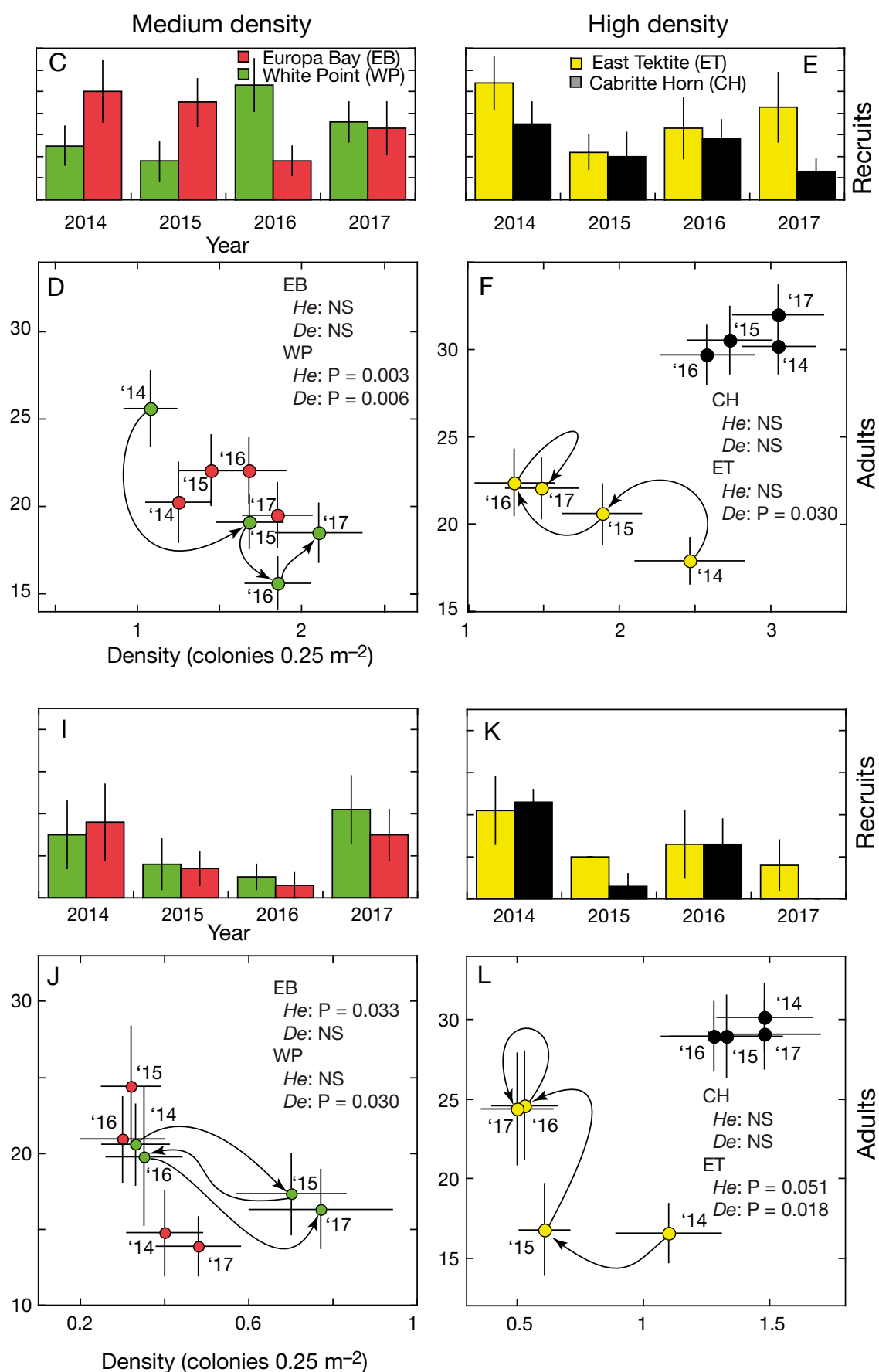

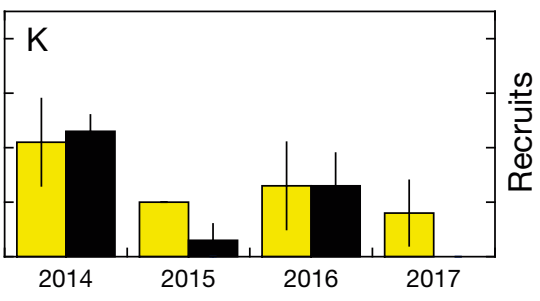

High density

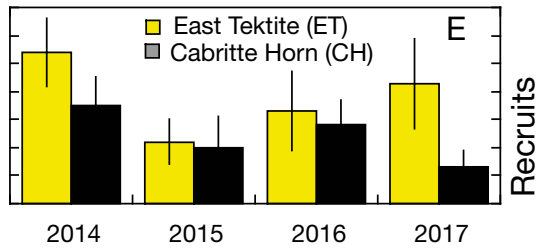

2014

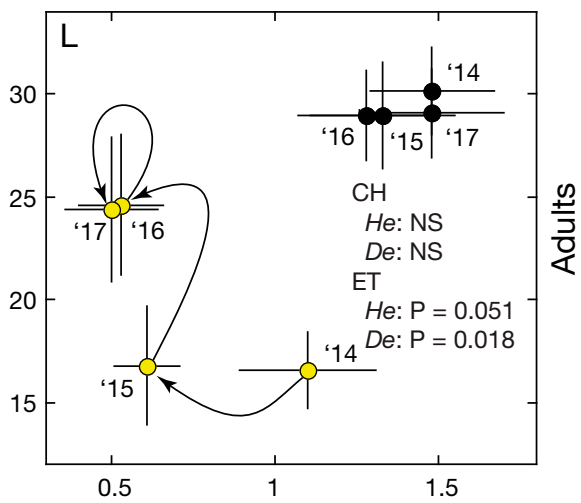

Fig. 2. Variation in octocoral communities among 4 years at 6 sites in St. John (Fig. 1), for (I) all taxa combined, and (II) Eunicea. Results shown for $(A, C, E, G, I, K)$ densities (colonies $\left.0.25 \mathrm{~m}^{-2}\right)$ of recruits $(\leq 5 \mathrm{~cm}$ tall), and $(\mathrm{B}, \mathrm{D}, \mathrm{F}, \mathrm{H}, \mathrm{J}, \mathrm{L})$ the height $(\mathrm{cm})$ and density (colonies $0.25 \mathrm{~m}^{-2}$ ) of adults (>5 cm tall) (scales differ among plots). Sites are grouped by octocoral densities into low, medium, and high density based on overall octocoral abundance (I) and abundance of Eunicea (II). Statistical contrasts among sites in Table 1. Frames $\mathrm{B}, \mathrm{D}, \mathrm{F}, \mathrm{H}, \mathrm{J}, \mathrm{L}$ show results for contrasts among years for height $(\mathrm{He})$ and density $(\mathrm{De})$, with years linked with arrows where densities differ among them

(Cabritte Horn, 2014 vs. 2016) to 1.9-fold (White Point, 2014 vs. 2017), and mean height from 1.1-fold (Cabritte Horn, 2017 vs. 2016) to 1.6-fold (White Point, 2014 vs. 2016). Mean density of recruits varied among years from 2.2-fold (West Tektite, 2014 vs. 2017), to 2.9-fold (White Point, 2015 vs. 2016). However, densities of adults only significantly differed among years at White Point (densities were lower in 
2014 vs. 2016 or 2017), and East Tektite (densities were higher in 2014 vs. 2016). Colony height and density of recruits differed among years at White Point (Table 1). Overall, at White Point, the mean density of adult colonies increased over time ( $\mathrm{r}=$ 0.96, df $=2, \mathrm{p}=0.039$ ), but no other associations between mean density and year, or mean height and year, were significantly associated with time $(\mathrm{p}>0.05)$.

\subsubsection{By genus}

Differences among times were less striking when the results were considered by genus (Fig. 2II and see Fig. S5 in the Supplement). For Eunicea, densities of adults differed among years at White Point, although differences among years could not be resolved in post hoc contrasts; there was a trend for the density of adult Eunicea to be greater in 2015 and 2017 than in 2014 and 2016. The height of Eunicea differed among years at Europa Bay ( $p=0.033$ ), and was taller in 2015 versus 2017, and the density of recruits differed among years at Cabritte Horn. For Antillogorgia, densities of adults differed among years at White Point, and at West Tektite, densities of recruits differed among years at White Point, and heights did not differ among years at any site (Table S1 in the Supplement). For Gorgonia, neither densities of adults nor their heights differed among years at any site, although densities of recruits differed among years at West Little Lameshur.

\subsection{Density dependence}

The relationships between recruitment and adult density, and between mean colony height and adult density, were examined for evidence of DD recruitment and ST, respectively. Recruitadult relationships were examined for all octocorals (pooled among taxa) and for Eunicea. The densities of Antillogorgia and Gorgonia recruits were too low for a meaningful test for DD recruitment. Neither the density of recruits nor per capita recruitment was associated with adult density ( $p>0.050)$ when abundances were pooled among genera (Fig. 3). For Eunicea, the density of recruits was positively associated with adult density in 2014, but per capita recruitment was inversely associated with density in 2014, 2015, and 2017 ( $p<$ 0.050; Fig. 3).
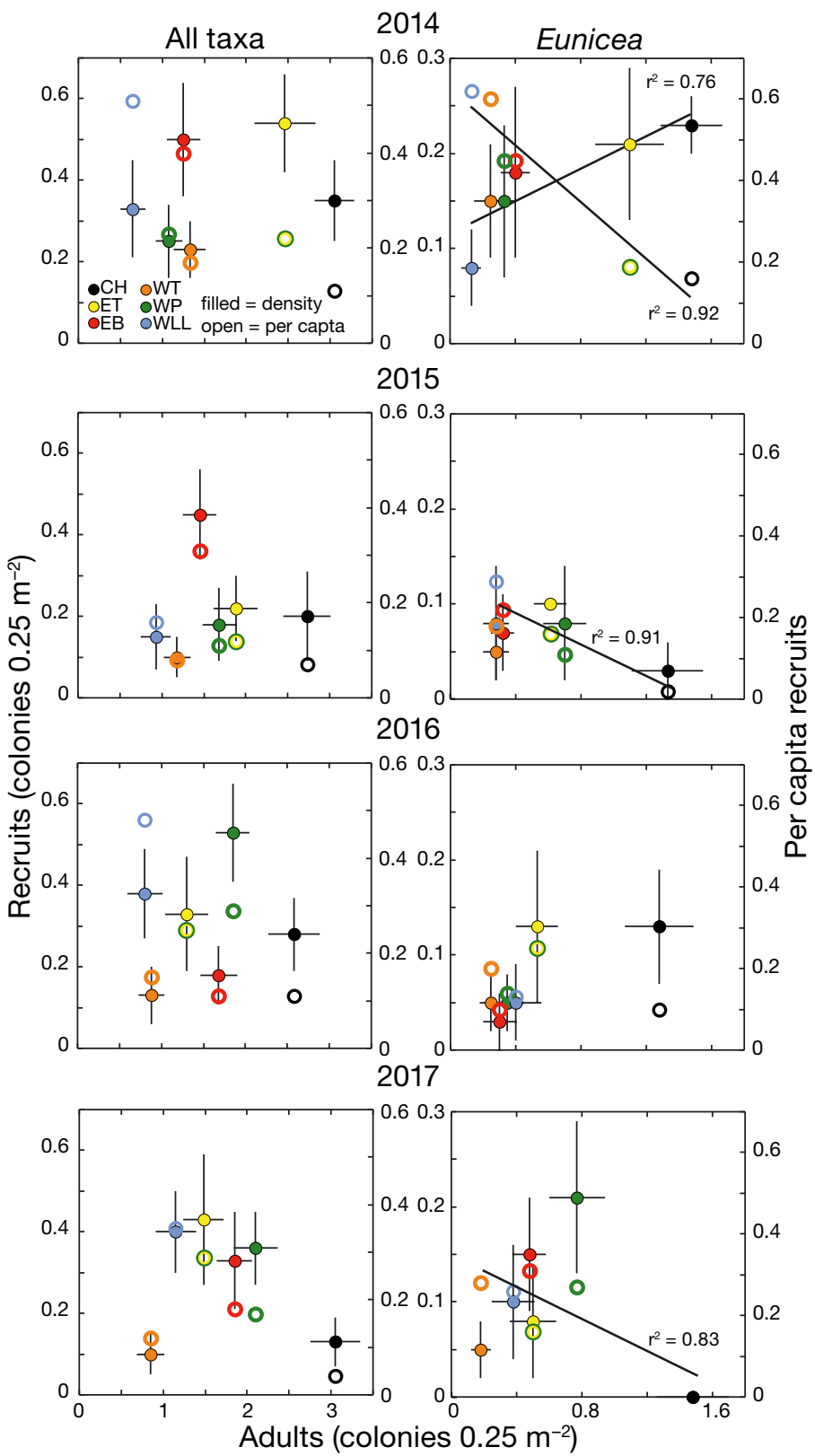

Fig. 3. Relationships between mean density of octocoral recruits (colonies $\leq 5 \mathrm{~cm}$ tall) and mean density of adult octocorals (colonies $>5 \mathrm{~cm}$ tall) for 6 sites (Fig. 1) over 4 years (2014-2017). Recruitment is shown as density (left ordinate, filled symbols) or per capita (right ordinate, open symbols), with \pm SE shown for densities of recruits and adults. Significant associations (as determined from Pearson correlations) are presented with Model I regression lines and $\mathrm{r}^{2}$ values

The effects of ST might be expected to appear through one or more of 3 types of evidence: (1) an inverse relationship between size and density at sites where there is high density of organisms (i.e. approximating a saturating biomass), (2) a trend over time at high-density sites for density of adults to decline, and their mean height to increase, and (3) at the scale of 
quadrats, and at high densities, an inverse relationship on a double logarithmic plot. For the sampling at a single point in time (e.g. 2014; Fig. 1), adult density and height differed among sites for pooled taxa, and for the 3 most common genera, except for Antillogorgia height (Table 1), but there was no association between size and density $(r \leq 0.69$, $d f=4, p \geq 0.13$ ). Therefore, when data were averaged at the level of sites there was no support of ST.

In the time-series analyses (Fig. 2), for pooled taxa, densities differed over time in 2 cases (Table 1). At East Tektite, where densities were categorized as 'high' (i.e. 1.3-2.5 colonies $0.25 \mathrm{~m}^{-2}$ ), there was a decline in density and a weak trend for increasing size, which conforms to expectations from selfthinning (Fig. 2F). There was no similar trend at the other high-density site, Cabritte Horn. At White Point, densities were categorized as 'medium' (i.e. 1.1-2.1 colonies $0.25 \mathrm{~m}^{-2}$ ), and here densities increased, and mean size declined (Fig. 2D). Densities and sizes of all octocorals (pooled among taxa) did not differ over time at the other 4 sites (Table 1). For Eunicea (Fig. 2II), at East Tektite ('high density', 0.5-1.1 colonies $0.25 \mathrm{~m}^{-2}$ ) densities declined and mean colony height increased, whereas at White Point ('medium density', 0.3-0.8 colonies $0.25 \mathrm{~m}^{-2}$ ), densities changed over time without any change in height (Fig. 2II, Table 1). Densities of Eunicea did not differ

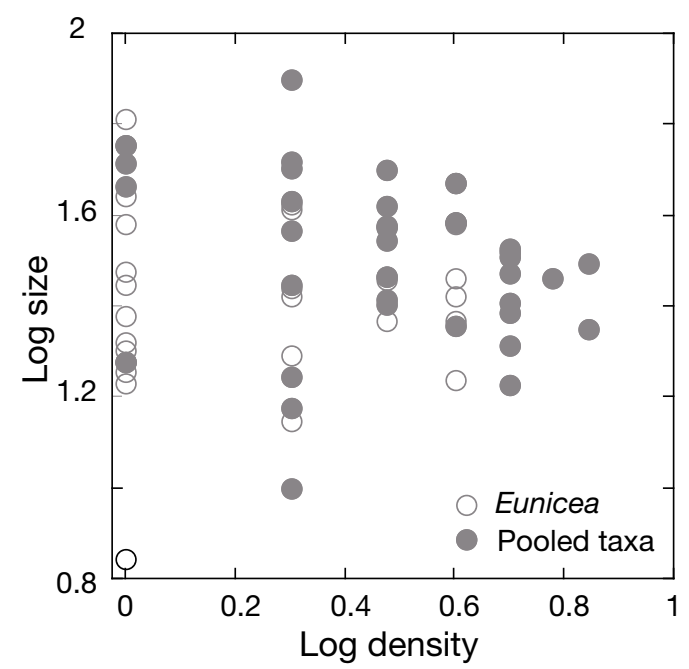

Fig. 4. Double logarithmic plot (as used in classic displays of self thinning, ST) showing log size (height, $\mathrm{cm}$ ) versus log density (colonies $0.25 \mathrm{~m}^{-2}$ ) for octocorals pooled among taxa (filled symbols) or for Eunicea (open symbols) for 2017 at Cabritte Horn. Neither association is significant ( $p \geq 0.168$ ), and $<6 \%$ of the variance is explained by the linear regression. This provides a representative plot for the site and year with the highest octocoral density (Fig. 1), which serves as a proxy for a saturating biomass under which ST is most likely to be expressed over time at the other 4 sites (Table 1). Antillogorgia densities changed over time at White Point and West Tektite, with the trend conforming to the predictions of ST at West Tektite, but not White Point (Table S1, Fig. S5). Densities of Gorgonia did not change over time at any site (Table S1). Therefore, there was limited evidence in support of ST in the temporal trends, largely as a result of Eunicea. Finally, ST should be evident at the quadrat scale when population densities are high, and most likely to approach saturating biomass. Densities were greatest at Cabritte Horn in 2017, and provided the conditions under which ST classically is most likely to be observed; there was no evidence of an inverse relationship between density and size at the scale of quadrats for this site and year (Fig. 4).

\section{DISCUSSION}

\subsection{Overview}

The present reefs have been studied for decades (Rogers et al. 2008, Edmunds \& Lasker 2016, Edmunds 2018), over which chronic and acute disturbances have been associated with the formation of a depleted scleractinian assemblage that is resistant to disturbances (Gross \& Edmunds 2015, Edmunds 2018). In contrast to the low abundances that characterize present-day scleractinian populations on these reefs, and the poor prognosis for their recovery (Edmunds 2018), octocorals on the same (and adjacent) reefs occur at high densities (Lenz et al. 2015, Edmunds \& Lasker 2016), and show signs of greater ecological resilience than scleractinians (Tsounis \& Edmunds 2017). Comparable data remain sparse across the Caribbean, but there is evidence from the Florida Keys (Ruzicka et al. 2013, Bartlett et al. 2018) of generality in the rising abundances of octocorals in St. John.

The ultimate causes of increased abundances of octocorals in St. John are likely to involve numerous environmental conditions, and the capabilities of octocorals, scleractinians, and other benthic taxa to respond to these conditions and to interact with one another. These capabilities are expressed through multiple demographic processes regulating population growth, any one of which is unlikely to fully 'explain' variation in population size. On the shallow reefs of St. John, arborescent octocorals currently occur at densities higher than in the recent past (Lenz et al. 2015, Edmunds \& Lasker 2016), but as we show here (and elsewhere; Edmunds et al. 2016), densities 
(of adults and recruits) and the mean heights of octocoral colonies vary over scales of kilometers and years. Analyses of the aforementioned trends for evidence of the effects of DD recruitment and ST revealed only limited support for these processes.

\subsection{Spatio-temporal variation}

Spatio-temporal variation in density and size of octocorals in St. John occurred among 4 years that were unremarkable in physical environmental conditions. From January 2014 to July 2017, St. John was not impacted by major hurricanes, mean daily seawater temperatures remained $\leq 30.3^{\circ} \mathrm{C}$, and relative to the last $46 \mathrm{yr}$, annual rainfall was slightly higher in 2014 and 2017 (2 and $17 \%$ above the upper 95\% CI, respectively), slightly lower in 2015 (13\% below the lower $95 \% \mathrm{CI}$ ), and within the $95 \%$ confidence intervals in 2016. Therefore, the variation in octocoral assemblages among the present study years at some sites is likely to reflect routine demographic processes such as the growth of recruits into adults, growth of adult colonies, and mortality attributed to detachment, diseases, and predation. As adults were defined by size (i.e. $>5 \mathrm{~cm}$ tall), their densities and sizes were not directly affected by recruitment (colonies $\leq 5 \mathrm{~cm}$ tall) in any one year, at least until recruits grew into the adult size class. During this study, the number of recruits growing into the adult size class probably did not vary greatly among years, as revealed by the relatively stable size-frequency distributions, and the absence of cohorts of recruits that transitioned through larger size classes (Fig. S4).

It is reasonable to infer that the differences in octocoral assemblages among sites in St. John reflected disparities in environmental conditions including factors such as flow speed, seawater temperature, underwater light regimes, and sedimentation. These conditions vary among sites, with generally higher wave energy and greater water clarity at the eastern versus western sites, and higher temperature and sedimentation at western versus eastern sites (Horst \& Edmunds 2010, Edmunds \& Gray 2014). These gradients are associated with variation in octocoral communities at 4 sites close to the present sites (Tsounis \& Edmunds 2017, Tsounis et al. 2018). Presumably, the environmental conditions that characterized the study reefs from 2014 to 2017 allowed site-based variation in octocoral performance to sum to octocoral assemblages that differed among some years and sites. To what extent can these effects be attributed to $\mathrm{DD}$ recruitment and $\mathrm{ST}$ ?

\subsection{Evidence for DD recruitment}

Demographic DD occurs when per capita population growth is affected by population size (Hixon et al. 2002). The effects can modulate mortality or recruitment, with direct DD providing feedback that can regulate population size (Hixon et al. 2002). Associations between the density of recruits and density of adults will occur under DD, but they are only diagnostic of DD if per capita recruitment covaries with adult density. Based on previous surveys conducted in 2013 and 2014 at the same sites as studied herein, augmented with 4 (2013) or 2 (2014) additional sites, and employing a more conservative definition of recruits (i.e. $\leq 4 \mathrm{~cm}$ tall), densityassociated recruitment was detected for octocorals (pooled among taxa), Gorgonia, and plexuarids (which includes Eunicea) (Privitera-Johnson et al. 2015). The curvilinear relationships describing recruit density as a function of adult density in this earlier analysis suggest DD recruitment, since per capita recruitment declined at higher adult densities (Fig. 2 in Privitera-Johnson et al. 2015). The present analysis is temporally more extensive than that of PriviteraJohnson et al. (2015), but spatially more restrictive (only 6 sites), and it uses a more liberal definition of recruit (i.e. $\leq 5 \mathrm{~cm}$ tall). Evidence of DD recruitment for Eunicea was found in 3 of 4 years, but not for all octocorals combined.

Recruitment (sensu Caley et al. 1996) concatenates the somewhat independent processes of larval supply, settlement to the benthos, and post-settlement survival, each of which has the potential for DD (e.g. Doropoulos et al. 2017). In demographically open populations, the supply of larvae cannot be DD (Hixon et al. 2002), since they are delivered from a variety of distant locations, but once at a specific site, both the settlement of pelagic larvae and their post-settlement success can be modulated by adult density (Doropoulos et al. 2017). Thus a DD signal of recruitment can be detected (i.e. for the first visible individuals in the population; Caley et al. 1996) for an open population, but the means by which this signal is generated will be unclear. With the exception of a few species, most Caribbean octocorals broadcast-spawn gametes (Kahng et al. 2011) and, therefore, the production of larvae from a site, which could be DD, will not affect supply of larvae to that site. However, a dense canopy such as could be created by stands of arborescent octocorals, could positively affect larval delivery to the benthos by modulating near-bottom flow speeds (Guizien \& Ghisalberti 2017), or might affect larval settlement and post-settlement survival. 
DD recruitment was observed for Eunicea in both the present study and in the study by PriviteraJohnson et al. (2015), with per capita rates declining with adult density in 3 of 4 years (Fig. 3). As most Eunicea populations (and most other Caribbean octocorals) are demographically open, evidence of DD recruitment is likely to reflect effects on settlement and post-settlement success. Such effects could arise from interference between adults and larvae through predation (i.e. with adult colonies providing a 'wall of mouths;' Fabricius \& Metzner 2004), allelopathy (Maida et al. 1995), or perhaps Janzen-Connell effects as occurs with the common scleractinian Orbicella faveolata (Marhaver et al. 2013). More complex mechanisms generating DD recruitment could arise from indirect effects of other members of the benthic community, particularly if they are positively affected by the density of adult octocorals. The gastropod Cyphoma gibbosum and the polychaete Hermodice carunculata potentially could drive these effects, as both are well known predators of octocorals (Birkeland \& Gregory 1975, Harvell \& Suchanek 1987, Vreeland \& Lasker 1989), and were observed consuming adult octocorals and their recruits on the shallow reefs of St. John.

\subsection{Evidence for $\mathrm{ST}$}

ST is a well-known scaling relationship developed for higher plants (Westoby 1981, 1984), which largely has been developed for monospecific even-aged stands (Weller 1987, Norberg 1988). High densities of trees approaching saturating biomass create resource competition among adjacent individuals, thus causing a reduction in tree density and concomitant increases in sizes of the trees remaining (Westoby 1984, Weller 1987). The attractiveness of this approach is striking for tropical octocorals on Caribbean reefs, where the above-benthos biomass of arborescent colonies evokes contrasts with terrestrial forests (Fig. 1B; Rossi et al. 2017). The detection of ST in Mediterranean octocorals (Linares et al. 2008) suggests that ST might be found among Caribbean octocorals (Nelson 2016). In such cases, ST might function at high octocoral densities (i.e. effectively at saturating biomass), through interference among swaying branches (Wahle 1985, Gambrel \& Lasker 2016) leading to polyp damage, lesions, and perhaps death, or potentially through resource acquisition with light availability and small particulate food being limited in dense stands of octocorals (Kim \& Lasker 1997, Coma et al. 2015).
The only evidence of ST that we observed was for Eunicea at East Tektite, where dense populations of adult colonies declined in density over $4 \mathrm{yr}$, and there was a trend for the mean height of colonies remaining to increase. Mean density at the site at the start in 2014 was among the highest recorded (Fig. 2), which increases the likelihood that biomass was saturating and conditions were favorable for the development of ST (Westoby 1984, Weller 1987). Although this pattern is consistent with $\mathrm{ST}$, it could also arise from alternative mechanisms, including for example, steady growth and constant mortality that were independent of adult density. Further, it is challenging to reconcile the trends at East Tektite as an example of ST, when octocoral densities were even higher at Cabritte Horn (Fig. 2), but neither density nor height changed over time in this location. It is important to note, however, that the theory of ST among plants is clearest for monospecific, even-aged stands (Weller 1987, Norberg 1988), and it has proven more difficult to detect in multi-species communities subject to continuous recruitment (Westoby 1984, Enquist \& Niklas 2001).

\subsection{Summary}

The present study used in situ surveys to evaluate the dynamics of octocoral assemblages over $4 \mathrm{yr}$ in St. John. By simultaneously evaluating how these assemblages exploited 2-dimensional space on the benthos through colony density, and 3-dimensional volume of the seawater above the benthos through density and height, the results were used to explore the possibility that assemblage dynamics were mediated, in part, by DD recruitment and $\mathrm{ST}$, as in their functional analogues of terrestrial forests (cited above). While the outcomes of the present analyses provide some limited support for DD recruitment and ST, neither provides a compelling explanation for the empirical dynamics of octocoral assemblages in St. John. There are strong parallels between marine animal forests and terrestrial forests, but the similarity may not extend to the relative importance of the processes controlling populations in the 2 systems. Given the likely complexity of factors regulating octocoral populations on present-day reefs, the current study serves as a valuable reminder of the limits to mensurative experimental analyses, and underscores the need for manipulative experiments that can test mechanistic explanations. 
Acknowledgements. This research was funded through the US National Science Foundation (OCE 13-32915, OCE 1334052, and DEB 13-50146), and was completed under permits issued by the Virgin Islands National Park (most recently VIIS-2017-SCI-0031 and VIIS-2017-SCI-0010). The research benefitted from discussions with L. Bramanti, G. Tsounis, and H. Nelson, and the fieldwork was assisted by E. Lenz, A. Ellis, J. Smolenski, D. Sternberg, H. Nelson, S. Zimmerman, A. Widrick, and A. Potter. We are grateful to V. Powell, S. Prosterman, and R. Lockhart for on-site logistical support, and the staff of the Virgin Islands Environmental Resource Station for making our visits to St. John productive and enjoyable. This is contribution number 284 of the CSUN marine biology program.

\section{LITERATURE CITED}

Babcock CR (1991) Comparative demography of three species of scleractinian corals using age-and size-dependent classifications. Ecol Monogr 61:225-244

Bartlett LA, Brinkhuis VI, Ruzicka RR, Colella MA, Lunz KS Leone EH, Hallock P (2018) Dynamics of stony coral and octocoral juvenile assemblages following disturbance on patch reefs of the Florida reef tract. In: Duque C, Camacho ED (eds) Corals in a changing world. IntechOpen, London, p 99-120

Birkeland C, Gregory B (1975) Foraging behavior and rates of feeding of gastropod, Cyphoma gibbosum. Nat His Mus Los Angel Cty Sci Bull 20:57-67

Bruno JF, Selig ER (2007) Regional decline of coral cover in the Indo-Pacific: timing, extent, and subregional comparisons. PLOS ONE 2:e711

* Bruno JF, Ellner SP, Vu I, Kim K, Harvell CD (2011) Impacts of Aspergillosis on sea fan coral demography: modeling a moving target. Ecol Monogr 81:123-139

* Caley MJ, Carr MH, Hixon MA, Hughes TP, Jones GP, Menge BA (1996) Recruitment and the local dynamics of open marine populations. Annu Rev Ecol Syst 27: $477-500$

Caswell H (2001) Matrix population models construction, analysis, and interpretation. Sinauer Associates, Sunderland, MA

Cau A, Bramanti L, Cannas R, Follesa MC and others (2016) Habitat constraints and self-thinning shape Mediterranean red coral deep population structure: implications for conservation practice. Sci Rep 6:23322

Coma R, Llorente-Llurba E, Serrano E, Gili J, Ribes M (2015) Natural heterotrophic feeding by a temperate octocoral with symbiotic zooxanthellae: a contribution to understanding the mechanisms of die-off events. Coral Reefs 34:549-560

Condit R, Hubbell SP, Foster RB (1994) Density dependence in two understory tree species in a neotropical forest. Ecology 75:671-680

Cramer D (1997) Fundamental statistics for social research. Routledge, New York, NY

Doropoulos C, Evensen NR, Gomez-Lemos LA, Babcock RC (2017) Density-dependent coral recruitment displays divergent responses during distinct early life-history stages. R Soc Open Sci 4:170082

Edmunds PJ (2013) Decadal-scale changes in the community structure of coral reefs of St. John, US Virgin Islands. Mar Ecol Prog Ser 489:107-123
Edmunds PJ (2018) The hidden dynamics of low coral cover communities. Hydrobiologia 818:193-209

Edmunds PJ, Elahi R (2007) The demographics of a 15-year decline in cover of the Caribbean reef coral Montastrea annularis. Ecol Monogr 77:3-18

Edmunds PJ, Gray SC (2014) The effects of storms, heavy rain, and sedimentation on the shallow coral reefs of St. John, US Virgin Islands. Hydrobiologia 734:143-158

Edmunds PJ, Lasker HR (2016) Cryptic regime shift in benthic community structure on shallow reefs in St. John, US Virgin Islands. Mar Ecol Prog Ser 559:1-12

Edmunds PJ, Tsounis G, Lasker HR (2016) Differential distribution of octocorals and scleractinians around St. John and St. Thomas, US Virgin Islands. Hydrobiologia 767: 347-360

* Enquist BJ, Niklas KJ (2001) Invariant scaling relations across tree-dominated communities. Nature 410:655-660

*Fabricius KE, Metzner J (2004) Scleractinian walls of mouths: predation on coral larvae by corals. Coral Reefs 23:245-248

FFrechette M, Lefaivre D (1995) On self-thinning in animals. Oikos 73:425-428

Gambrel B, Lasker HR (2016) Interactions in the canopy among Caribbean reef octocorals. Mar Ecol Prog Ser 546: 85-95

* Gomez CG, Guzman HM, Gonzalez A (2018) Stability and dynamic properties of octocoral communities in the Tropical Eastern Pacific. Mar Ecol Prog Ser 588:71-84

* Graham NAJ, Nash KL, Kool JT (2011) Coral reef recovery dynamics in a changing world. Coral Reefs 30:283-294

*Goss K, Edmunds PJ (2015) Stability of Caribbean coral communities quantified by long-term monitoring and autoregression models. Ecology 96:1812-1822

Guest JR, Edmunds PJ, Gates RD, Kuffner IB and others (2018) A framework for identifying and characterizing coral reef 'oases' against a backdrop of degradation. J Appl Ecol 55:2865-2875

GGinez R (2005) A review on self-thinning in mussels. Rev Biol Mar Oceanogr 40:1-6

Guizien K, Ghisalberti M (2017) Living in the canopy of the animal forest: physical and biogeochemical aspects. In: Rossi S, Bramanti L, Gori A, Orejas C (eds) Marine animal forests: the ecology of benthic biodiversity hotspots. Springer International Publishing, Cham, p 812-834

*Haldane JBS (1953) Some animal life tables. J Inst Actuar 79:83-89

Harms KE, Wright SJ, Calderon O, Hernandez A, Herre EA (2000) Pervasive density-dependent recruitment enhances seedling diversity in a tropical forest. Nature 404: 493-495

* Harvell CD, Suchanek TH (1987) Partial predation on tropical gorgonians by Cyphoma gibbosum (Gastropoda). Mar Ecol Prog Ser 38:37-44

* Hixon MA, Pacala SW, Sandin SA (2002) Population regulation: historical context and contemporary challenges of open vs. closed systems. Ecology 83:1490-1508

KHolbrook SJ, Adam TC, Edmunds PJ, Schmitt RJ and others (2018) Recruitment drives spatial variation in recovery rates of resilient coral reefs. Sci Rep 8:7338

*Horst G, Edmunds PJ (2010) Spatio-temporal variation in seawater characteristics in a semi-enclosed bay in St. John, U.S. Virgin Islands. Caribb J Sci 46:54-63

*Hughes TP (1984) Population dynamics based on individual size rather than age: a general model with a reef coral 
example. Am Nat 123:778-795

Hughes TP, Jackson JBC (1985) Population dynamics and life histories of foliaceous corals. Ecol Monogr 55:141-166

Hughes TP, Tanner JE (2000) Recruitment failure, life histories, and long-term decline of Caribbean corals. Ecology 81:2250-2263

* Hughes TP, Anderson KD, Connolly SR, Heron SF and others (2018a) Spatial and temporal patterns of mass bleaching of corals in the Anthropocene. Science 359:80-83

*Hughes TP, Kerry JT, Baird AH, Connolly SR and others (2018b) Global warming transforms coral reef assemblages. Nature 556:492-496

Jackson JBC, Donovan MK, Cramer KL, Lam VV (eds) (2014) Status and trends of Caribbean coral reefs: 19702012. Global Coral Reef Monitoring Network, Gland

Kahng SE, Benayahu Y, Lasker HR. (2011) Sexual reproduction in octocorals. Mar Ecol Prog Ser 443:265-283

Kim K, Lasker HR (1997) Flow mediated resource competition in the suspension feeding gorgonian Plexaura homomalla (Esper). J Exp Mar Biol Ecol 215:49-64

L Lasker HR (1990) Clonal propagation and population dynamics of a gorgonian coral. Ecology 71:1578-1589

Lasker HR (2013) Recruitment and resilience of a harvested Caribbean octocoral. PLOS ONE 8:e74587

Lenz EA, Bramanti L, Lasker HR, Edmunds PJ (2015) Longterm variation of octocoral populations in St. John, US Virgin Islands. Coral Reefs 34:1099-1109

Lessios HA, Kessing BD, Pearse JS (2001) Population structure and speciation in tropical seas: global phylogeography of the sea urchin Diadema. Evolution 55:955-975

Levitan DR, Edmunds PJ, Levitan KE (2014) What makes a species common? No evidence of density-dependent recruitment or mortality of the sea urchin Diadema antillarum after the 1983-1984 mass mortality. Oecologia 175:117-128

Linares C, Coma R, Mariani S, Diaz D, Hereu B, Zabala M (2008) Early life history of the Mediterranean gorgonian Paramuricea clavata: implications for population dynamics. Invertebr Biol 127:1-11

Lonsdale WM (1990) The self-thinning rule: dead or alive? Ecology 71:1373-1388

Maida M, Sammarco PW, Coll JC (1995) Effects of soft corals on scleractinian coral recruitment. I: Directional allelopathy and inhibition of settlement. Mar Ecol Prog Ser 121: 191-202

Marhaver KL, Vermeij MJA, Rohwer F, Sandin SA (2013) Janzen-Connell effects in a broadcast-spawning Caribbean coral: distance-dependent survival of larvae and settlers. Ecology 94:146-160

McCallum HI (1990) Effects of predation on Acanthaster: age-structured metapopulation models. In: Bradbury $\mathrm{R}$ (ed) Acanthaster and the coral reef: a theoretical perspective. Lect Notes Biomath. Springer, Berlin, p 208-219

McMurray SE, Pawlik JR, Finelli CM (2017) Demography alters carbon flux for a dominant benthic suspension feeder, the giant barrel sponge, on Conch Reef, Florida Keys. Funct Ecol 31:2188-2198

Murdoch WM (1994) Population regulation in theory and practice. Ecology 75:271-287

Nelson HR (2016) From trees to octocorals: the role of phenotypic integration, shading, and self-thinning in underwater animal forests. MSc thesis, California State University Northridge, Northridge, CA

Norberg RA (1988) Theory of growth geometry of plants and self-thinning of plant populations: geometric similarity, elastic similarity, and different growth modes of plant parts. Am Nat 131:220-256

Norström AV, Nyström M, Lokrantz J, Folke C (2009) Alternative states on coral reefs: beyond coral-macroalgal phase shifts. Mar Ecol Prog Ser 376:295-306

Pratchett MS (2005) Dynamics of an outbreak population of Acanthaster planci at Lizard Island, northern Great Barrier Reef (1995-1999). Coral Reefs 24:453-462

* Privitera-Johnson K, Lenz EA, Edmunds PJ (2015) Densityassociated recruitment in octocoral communities in St. John, US Virgin Islands. J Exp Mar Biol Ecol 473:103-109

* Riegl B, Cavalcante G, Bauman AG, Feary DA, Steiner S, Purkis S (2017) Demographic mechanisms of reef coral species winnowing from communities under increased environmental stress. Front Mar Sci 4:344

Roff G, Mumby PJ (2012) Global disparity in the resilience of coral reefs. Trends Ecol Evol 27:404-413

Rogers CS, Miller J, Muller EM, Edmunds PJ and others (2008) Ecology of coral reefs in the US Virgin Islands. In: Riegl BM, Dodge RE (eds) Coral reefs of the USA. Springer, Berlin, p 303-373

Rossi S, Bramanti L, Gori A, Orejas C (2017) An overview of the animal forests of the world. In: Rossi S, Bramanti L, Gori A, Orejas C (eds) Marine animal forests. Springer, Cham, p 26-52

Kuzicka RR, Colella MA, Porter JW, Morrison JM and others (2013) Temporal changes in benthic assemblages on Florida Keys reefs 11 years after the 1997/1998 El Niño. Mar Ecol Prog Ser 489:125-141

* Sale PF, Tolimieri N (2000) Density dependence at some time and place? Oecologia 124:166-171

Sanchez JA (2017) Diversity and evolution of octocoral animal forests at both sides of tropical America. In: Rossi S, Bramanti L, Gori A, Orejas C (eds) Marine animal forests. Springer, Cham, p 111-143

Stobart B, Teleki K, Buckley R, Downing N, Callow M (2005) Coral recovery at Aldabra Atoll, Seychelles: five years after the 1998 bleaching event. Philos Trans R Soc A 363: 251-255

Thomas CD, Cameron A, Green RE, Bakkenes M and others (2004) Extinction risk from climate change. Nature 427: $145-148$

Tsounis G, Edmunds PJ (2017) Three decades of coral reef community dynamics in St. John, USVI: a contrast of scleractinians and octocorals. Ecosphere 8:e01646

Tsounis G, Edmunds PJ, Bramanti L, Gambrel B, Lasker HR (2018) Variability of size structure and species composition in Caribbean octocoral communities under contrasting environmental conditions. Mar Biol 165:29

* Urban MC, Bocedi G, Hendry AP, Mihoub JB and others (2016) Improving the forecast for biodiversity under climate change. Science 353:1113-1122

* van Hooidonk RV, Maynard JA, Manzello D, Planes S (2014) Opposite latitudinal gradients in projected ocean acidification and bleaching impacts on coral reefs. Glob Change Biol 20:103-112

Vreeland HV, Lasker HR (1989) Selective feeding of the polychaete Hermodice carunculata Pallas on Caribbean gorgonians. J Exp Mar Biol Ecol 129:265-277

Wahle CM (1985) Habitat-related patterns of injury and mortality among Jamaican gorgonians. Bull Mar Sci 37: 905-927

Weller DE (1987) A reevaluation of the $-3 / 2$ power rule of 
plant self-thinning. Ecol Monogr 57:23-43

Westoby M (1981) The place of the self-thinning rule in population dynamics. Am Nat 118:581-587

Westoby M (1984) The self-thinning rule. Adv Ecol Res 14: 167-225

White J (1981) The allometric interpretation of the selfthinning rule. J Theor Biol 89:475-500

Wills C, Condit R, Foster RB, Hubbell SP (1997) Strong den-

Editorial responsibility: Karen Miller,

Hobart, Tasmania, Australia sity- and diversity-related effects help to maintain tree species diversity in a neotropical forest. Proc Natl Acad Sci USA 94:1252-1257

Yoshioka PM (1996) Variable recruitment and its effects on the population and community structure of shallowwater gorgonians. Bull Mar Sci 59:433-443

Zar JH (2010) Biostatistical analysis, 5th edn. Pearson, Upper Saddle River, NJ

Submitted: October 8, 2018; Accepted: February 24, 2019

Proofs received from author(s): March 26, 2019 